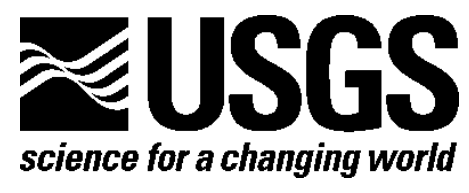

Prepared in cooperation with the U.S. Department of the Navy Geothermal Program Office

\title{
A Time-Lapse Gravity Survey of the Coso Geothermal Field, China Lake Naval Air Weapons Station, California
}

By G. Phelps, C. Cronkite-Ratcliff, and K. Blake

Open-File Report 2018-1053

U.S. Department of the Interior

U.S. Geological Survey 


\section{U.S. Department of the Interior RYAN K. ZINKE, Secretary}

\section{U.S. Geological Survey \\ William H. Werkheiser, Deputy Director exercising the authority of the Director}

U.S. Geological Survey, Reston, Virginia: 2018

For more information on the USGS—-the Federal source for science about the Earth, its natural and living resources, natural hazards, and the environment-visit https://www.usgs.gov/ or call 1-888-ASK-USGS (1-888-275-8747).

For an overview of USGS information products, including maps, imagery, and publications, visit https://store.usgs.gov/.

Any use of trade, firm, or product names is for descriptive purposes only and does not imply endorsement by the U.S. Government.

Although this information product, for the most part, is in the public domain, it also may contain copyrighted materials as noted in the text. Permission to reproduce copyrighted items must be secured from the copyright owner.

Suggested citation:

Phelps, G., Cronkite-Ratcliff, C., and Blake, K., 2018, A time-lapse gravity survey of the Coso geothermal field, China Lake Naval Air Weapons Station, California: U.S. Geological Survey Open-File Report 2018-1053, 25 p., https://doi.org/10.3133/ofr20181053.

ISSN 2331-1258 (online) 


\section{Acknowledgments}

This work was made possible by support from the U.S. Department of the Navy Geothermal Program Office. The report was greatly improved by reviews from Dr. A. Sabin of the Navy Geothermal Program Office and Dr. D. Scheirer, Dr. M. Poland, and Dr. M. Erdman (editor) of the U.S. Geological Survey. 


\section{Contents}

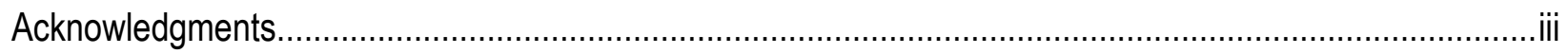

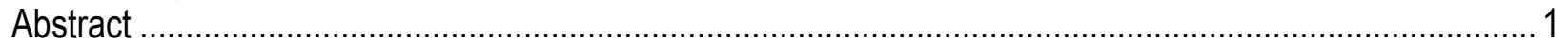

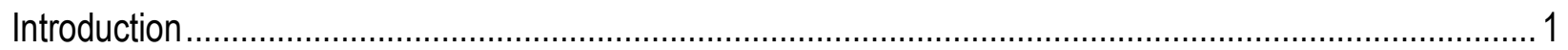

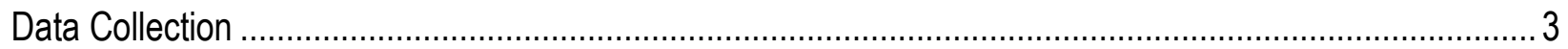

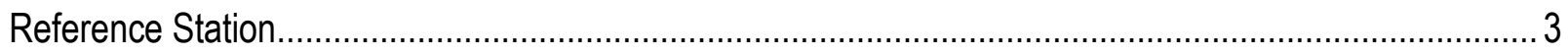

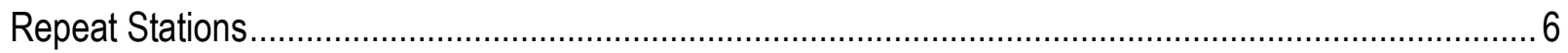

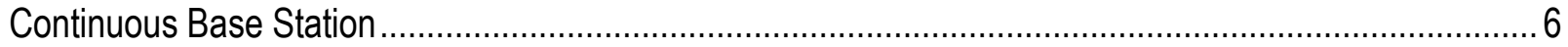

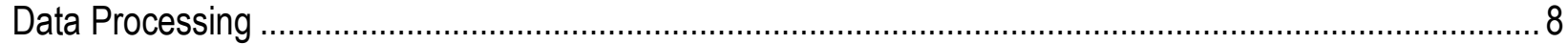

Modifications to Standard Corrections ........................................................................................... 8

Correction for Secondary Tidal Acceleration ................................................................................ 8

Linear Daily Correction Based on Repeat Stations …………....................................................... 10

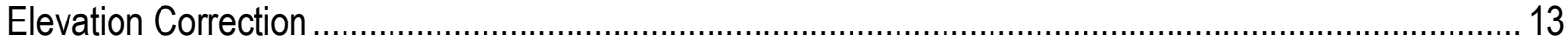

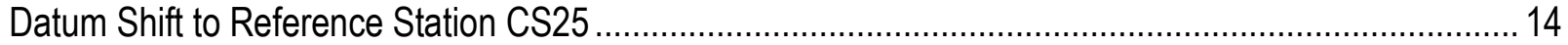

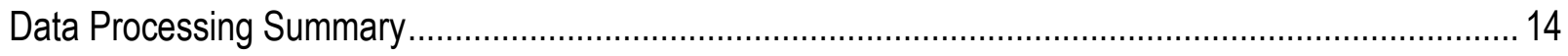

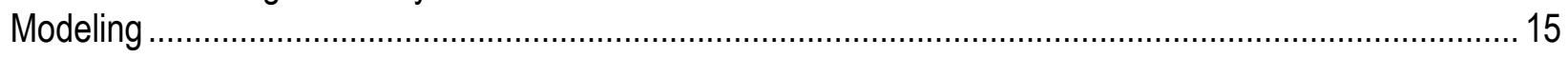

Results

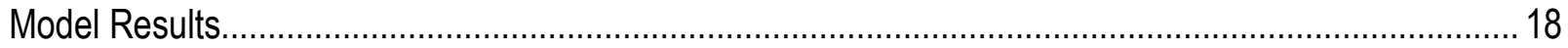

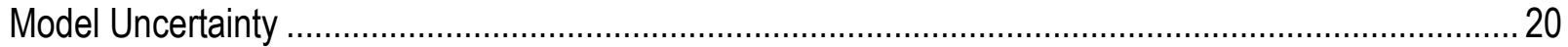

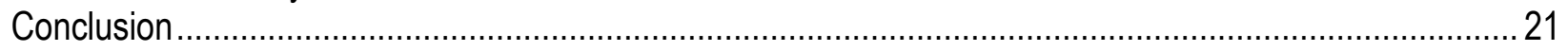

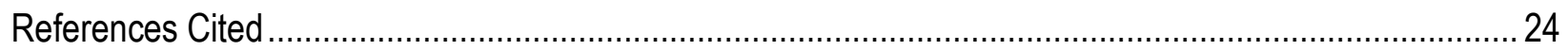




\section{Figures}

1. Map of Coso Basin, south-central California, showing location of the Coso geothermal field...........2

2. Map of Coso Basin showing time-lapse gravity stations near the Coso geothermal field ................. 4

3. Map of Coso Basin showing gravity changes from 1996 to 2016 at time-lapse gravity stations ........5

4. Photograph of Scintrex CG5 gravimeters at the China Lake Naval Air Weapons Station................. 7

5. Graph of gravimetric data collected from continuous base station CG5D over the survey period ....7

6. Graph of gravimetric data residuals collected from continuous base station CG5D over survey period after removal of effects of instrument drift, showing periodicity of secondary tidal accelerations

7. Graph of gravimetric data residuals collected from continuous base station CG5D over survey period after removal of effects of instrument drift and secondary tidal acceleration.

8. Graph of apparent linear instrument drift of roving gravimeter at repeat station GPOBASE and reference station CS25

9. Graph of apparent daily-drift rate for measurement pairs at all repeat gravity stations where both measurements were taken on the same day

10. Histogram of gravity differences between repeat measurements before within-day drift correction and after daily-drift correction

11. Map of gravity differences from 1996 to 2016 measured at gravity stations in the vicinity of the Coso geothermal field in the Coso Basin....

12. Graph of gravity differences from 1996 to 2016 measured at station CER1, showing decrease in relative gravity over time.

13. Map of modeled water-table drawdown in the Coso Basin.

14. Three-dimensional plot of the calculated gravity anomaly in the Coso geothermal field ..................20

\section{Tables}

1. Location and relative gravity values for stations measured in this study...... 


\title{
A Time-Lapse Gravity Survey of the Coso Geothermal Field, China Lake Naval Air Weapons Station, California
}

\author{
By G. Phelps, C. Cronkite-Ratcliff, and K. Blake
}

\begin{abstract}
We have conducted a gravity survey of the Coso geothermal field to continue the time-lapse gravity study of the area initiated in 1991. In this report, we outline a method of processing the gravity data that minimizes the random errors and instrument bias introduced into the data by the Scintrex CG- 5 relative gravimeters that were used. This method includes the removal of a secondary tidal effect, measured at a continuous base station, not captured in the primary tidal corrections typically applied by using Longman's formula from 1959. The method also minimizes the potentially significant effect of daily instrument drift by using multiple repeat gravity measurements throughout the day to characterize the linear component of the drift. After processing, the standard deviation of the data was estimated to be \pm 13 microGals $(\mu \mathrm{Gal})$. These data reveal that the negative gravity anomaly over the Coso geothermal field, centered on gravity station CER1, is continuing to increase in magnitude over time. Preliminary modeling indicates that water-table drawdown at the location of CER1 is between 65 and 326 meters (m) over the last two decades. We note, however, that several assumptions on which the model results depend, such as constant elevation and free-water level over the study period, still require verification.
\end{abstract}

\section{Introduction}

The Coso geothermal field is in the Coso Range, a small mountainous region in California east of the southern Sierra Nevada (fig. 1). The Coso Range is composed of pre-Cenozoic basement rocks disconformably overlain by Cenozoic volcanic and sedimentary rocks. Granitic, dioritic, and gabbroic plutons and metamorphic rocks make up the pre-Cenozoic basement and the overlying volcanic and sedimentary rocks range in age from Pliocene to Pleistocene (Duffield and others, 1980).

The Coso volcanic field, within the Coso Range, comprises 38 rhyolite domes, flows, and epiclastic successions (Bacon and Duffield, 1980). The ages of these domes and flows range from $\sim 700,000$ to 60,000 years (Simons and others, 2009). High permeability from fracturing provides drilling targets for the geothermal site (Sabin and others, 2016). The Coso geothermal field has been in production since 1987 and has a capacity of 270 megawatts (MW) (Sabin and others, 2016).

Time-lapse gravity measurements have been used to estimate the changes in free-water level in the Coso geothermal system since the 1990s, but most recently a survey was performed in 2013 (Woolf, 2013). "Free-water level" is defined as the hypothetical groundwater level if all the subsurface water were unconfined (Woolf, 2013). Because the absence of pore water makes the bulk density of the unsaturated rocks less than that of the saturated rocks, the local gravity anomaly will decrease if the mass in the geothermal field decreases. Assuming that any density effect from subsurface steam is negligible and estimating the rock porosity, the difference in density between saturated and unsaturated rocks can then be estimated, and the change in free-water level can then be modeled from the magnitude 


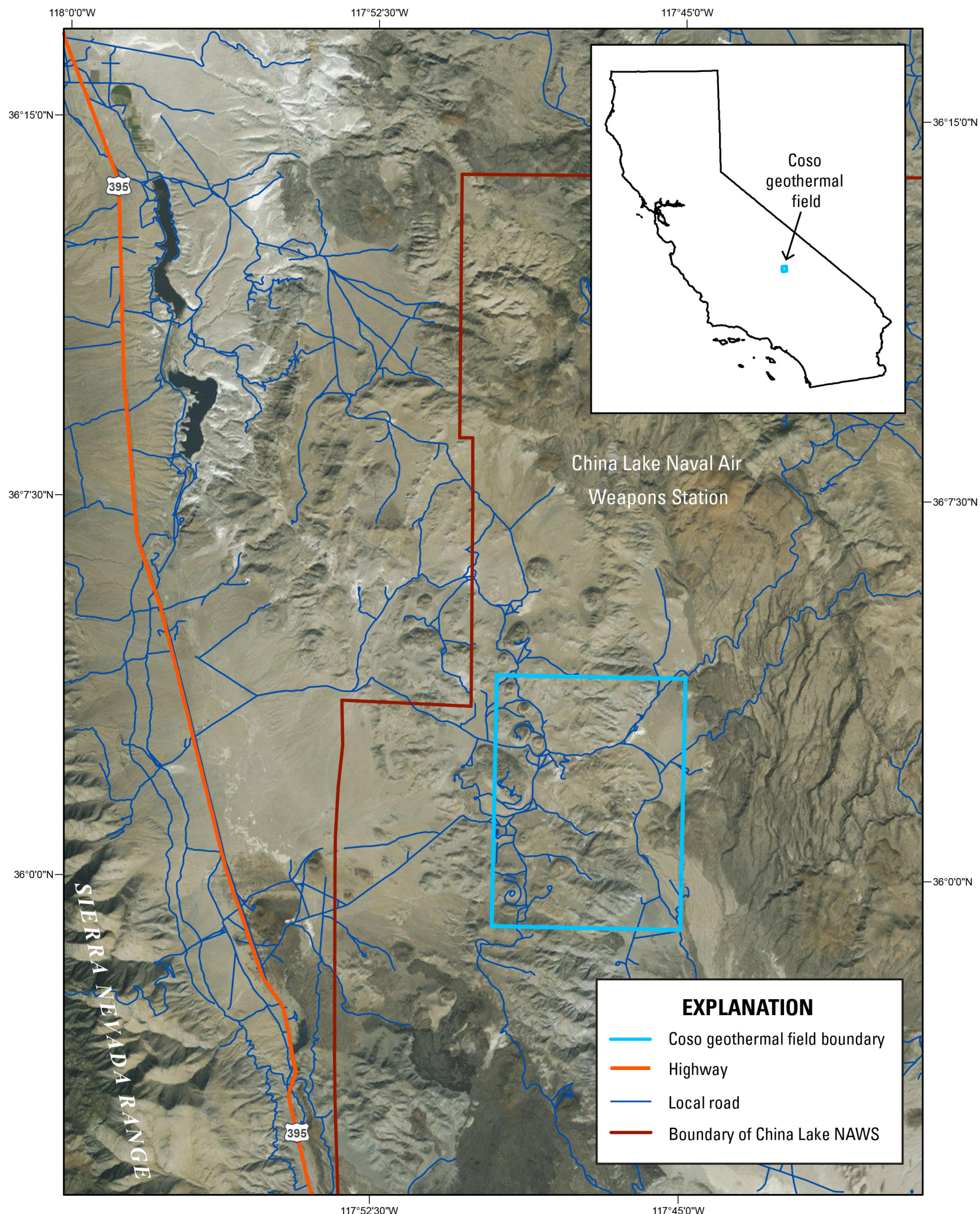

Figure 1. Map of Coso Basin, south-central California, showing location of the Coso geothermal field (blue rectangle). NAWS, China Lake Naval Air Weapons Station. Map imagery from Esri (2017) and its licensures. 
of the gravity decrease, assuming that mass loss from mineral dissolution is also negligible. The true relation between the magnitude of the gravity decrease and the decrease in free-water level cannot be exactly known because the true rock porosities, saturation, and any mineral dissolution or precipitation vary spatially and are insufficiently known throughout most of the study area.

In May 2016, the U.S. Geological Survey and the U.S. Department of the Navy's Geothermal Program Office (GPO) jointly conducted a time-lapse gravity survey of the Coso geothermal field, building upon two decades of previous time-lapse gravity surveys archived by the GPO. Recent data collection and modeling was summarized by Woolf (2013). The goal of our survey was to measure and interpret gravity changes, if any, since the previous survey and to establish best practices for gravity data collection within and around the Coso geothermal field. An objective of time-lapse gravity measurements in the Coso geothermal field is to better understand mass changes, interpreted as changes in free-water level, associated with geothermal production.

We outline best practices for data collection and reduction, specifically focused on increasing the precision of the collected data by using ample redundant gravity stations to characterize instrument drift, and including a secondary tidal correction in addition to the primary tidal correction that is typically applied to gravity data. We also construct a preliminary model of the decreases in free-water level on the basis of the gravity data. Our approach follows that outlined by Woolf (2013), modeling the difference between the shape of the current time-lapse gravity anomaly and previous time-lapse gravity anomalies. This preliminary modeling effort is not a rigorous investigation of mass changes in the Coso geothermal field, which would require the incorporation of data and modeling from other sources, such as Global Positioning System (GPS) and interferometric synthetic-aperture radar (InSAR), but is one component of such a potential future investigation.

\section{Data Collection}

Gravity measurements have been made at more than 150 gravity stations located in and around the Coso geothermal field in recent decades. Over that timespan, some of these stations have been destroyed, typically by construction, and others are now inaccessible owing to land restrictions. During an 8-day survey period in May 2016, we reoccupied 97 of these gravity stations (figs. 2, 3). Two Scintrex CG5 gravimeters were used: one to collect data at field stations, and one to measure the gravity at a reference station throughout the day. Multiple repeat measurements (repeat stations) were made throughout a given survey day to help constrain the instrument drift of the gravimeters and to increase the precision of the gravity readings at these repeat stations. All measurements were tied to a convenient local gravity reference station near the survey area but outside the central part of the Coso geothermal field.

\section{Reference Station}

The reference station served as the gravity datum for our survey, and all other stations were measured relative to that reference station. Because time-lapse gravity is concerned with only relative gravity differences, the data need not be tied to a gravity network, such as IGSN71 (Morelli, 1974). The reference station should be away from the region of interest because the station is assumed to be unchanging over the time period of measurements, and so should be beyond the influence of the changing gravity field that is the focus of the study.

We used station CS25, located near the west edge of the study area (fig. 2), as the reference station because of its proximity to the study area, its convenience for measurements (it is located next to the access road in and out of the geothermal plant, so it can be measured upon entry and exit to the site) 


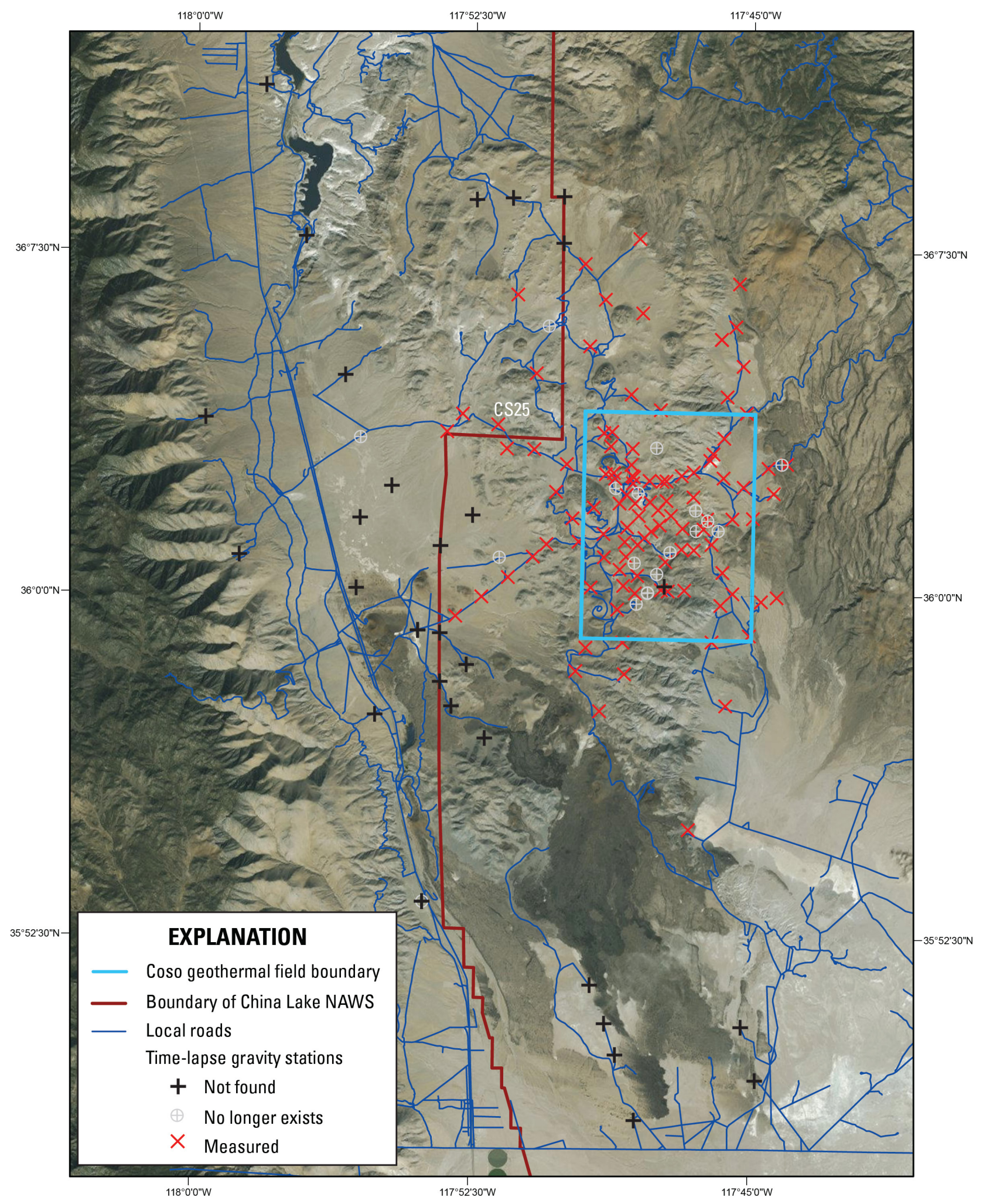

Figure 2. Map of Coso Basin, south-central California, showing locations of time-lapse gravity stations near the Coso geothermal field, 97 of which were reoccupied for the spring 2016 survey. Some gravity stations have been destroyed by construction activity. NAWS, China Lake Naval Air Weapons Station. Map imagery from Esri (2017) and its licensures. 


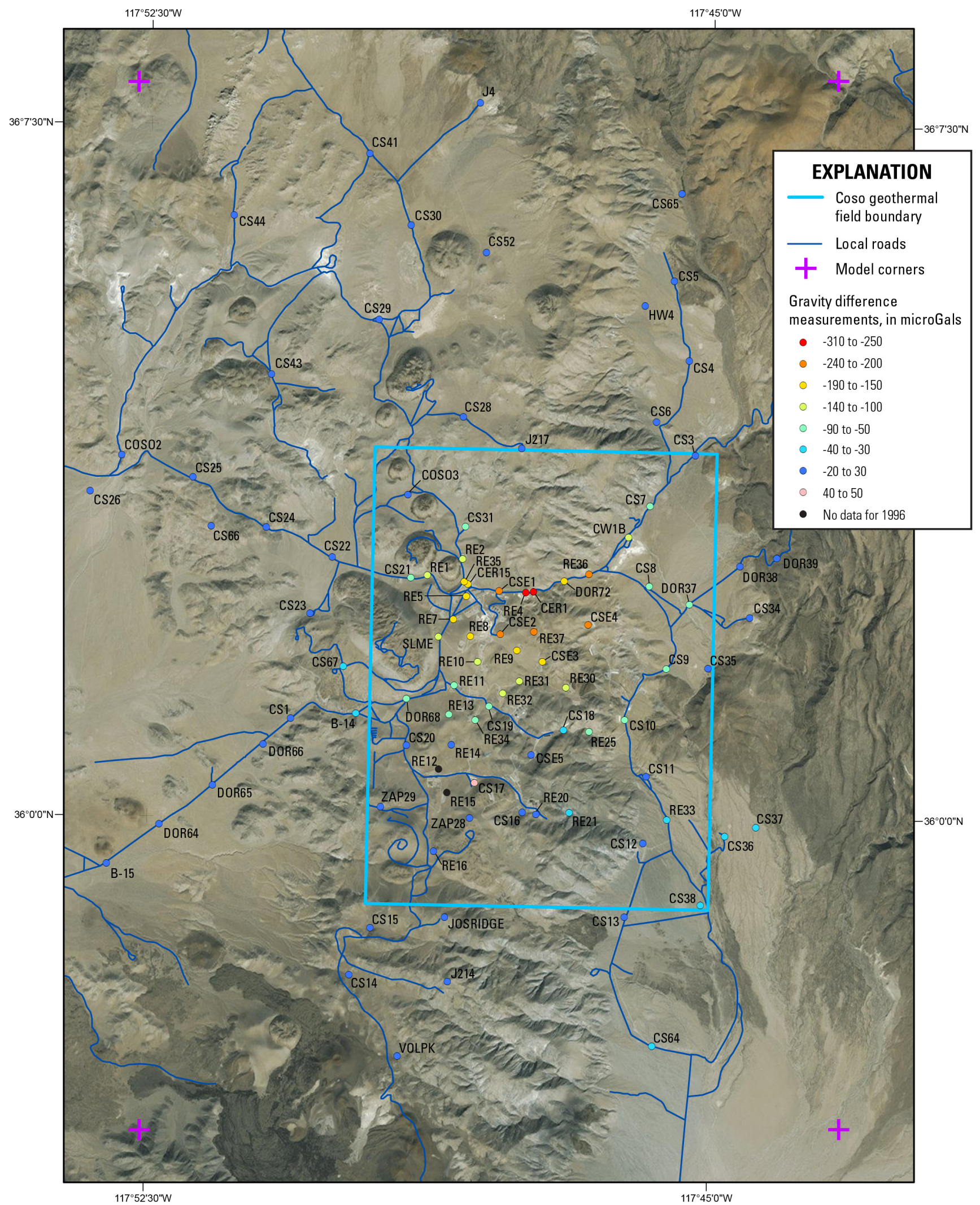

Figure 3. Map of Coso Basin, south-central California, showing gravity changes from 1996 to 2016 at time-lapse gravity stations near the Coso geothermal field. Map imagery from Esri (2017) and its licensures. 
and its location away from the main geothermal field, making it unlikely to be affected by changes in

the gravity field. Station CS25 proved to be a stable, convenient reference station and we recommend its use as a reference station in future studies.

\section{Repeat Stations}

Repeat stations are those stations other than the reference station and the continuous base station that are measured by the roving gravimeter twice or more within a survey day. Measurements are taken at these repeat stations to assess the behavior of the instrument throughout the day. Repeat stations are distinguished from continuous base stations, which are occupied continuously by the base gravimeter to monitor secondary tidal effects. Repeat stations can be the same station measured repeatedly at regular intervals, typically every 2 hours, throughout the survey day. However, it may not be convenient or even possible to return to the same station regularly throughout the day, in which case "repeat station" refers to any station(s) that are repeated. As long as a sufficient number of repeat measurements are made, the instrument behavior can be assessed (see below) during a given day. For our survey, we repeated measurements at different stations throughout the day as was convenient.

\section{Continuous Base Station}

The continuous base station is a second gravimeter, set up in a stable location, that reads in place continuously over periods of days and longer. Because the gravimeter is stable, it can be used to assess secondary tidal effects (Scintrex, 2006) not accounted for in Longman's (1959) formula and any other noise, such as long-period disturbances caused by earthquakes, occurring simultaneously with the roving gravimeter and similarly affecting it. These sources of noise can then be subtracted from the roving gravimeter data, analogously to subtracting the diurnal magnetic signal measured at a magnetic base station from aeromagnetic data collected simultaneously over a neighboring region.

In our survey, the continuous base station (fig. 4) was located in the GPO building at the China Lake Naval Air Weapons Station, adjacent to Ridgecrest, Calif. ( 50 kilometers, km, to the south). To establish a continuous base station, we placed a second gravimeter in a safe, environmentally shielded area with access to continuous electrical power; it recorded measurements at 90 -second intervals while our survey was in progress. The continuous base station was set up to read continuously (day and night) for the duration of the survey; it was paused briefly once in the morning and once in the evening to relevel the gravimeter and check the data. The base gravimeter observations recorded instrument drift and secondary tidal effects, interpreted as such because of their daily periodicity, present after the removal of the primary tidal correction (Longman, 1959). Corrections were synchronized to the roving gravimeter according to their time stamp. The gravimetric data collected at the continuous base station over the weeklong survey period are plotted in figure 5. 


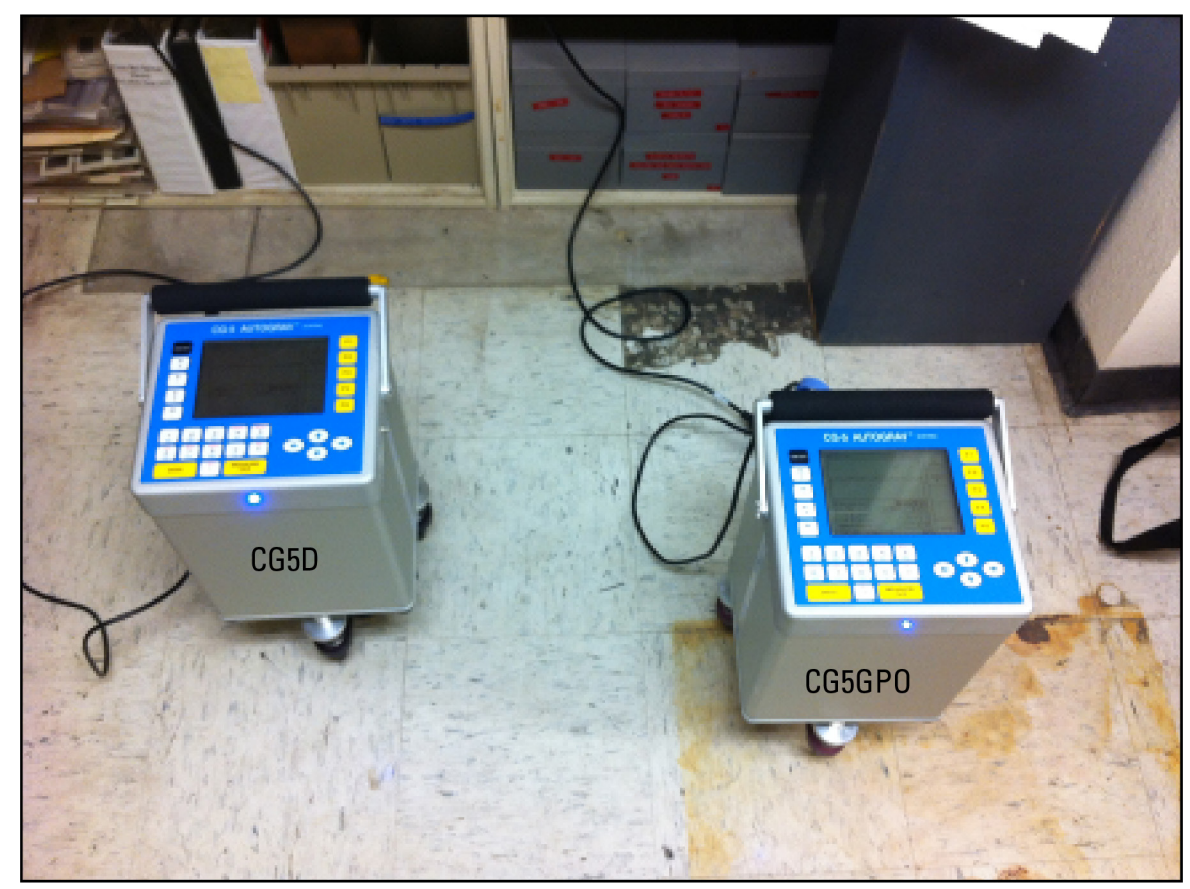

Figure 4. Photograph of Scintrex CG5 gravimeters at base station in the U.S. Department of the Navy Geothermal Program Office building at the China Lake Naval Air Weapons Station. CG5D is the continuous base gravimeter.

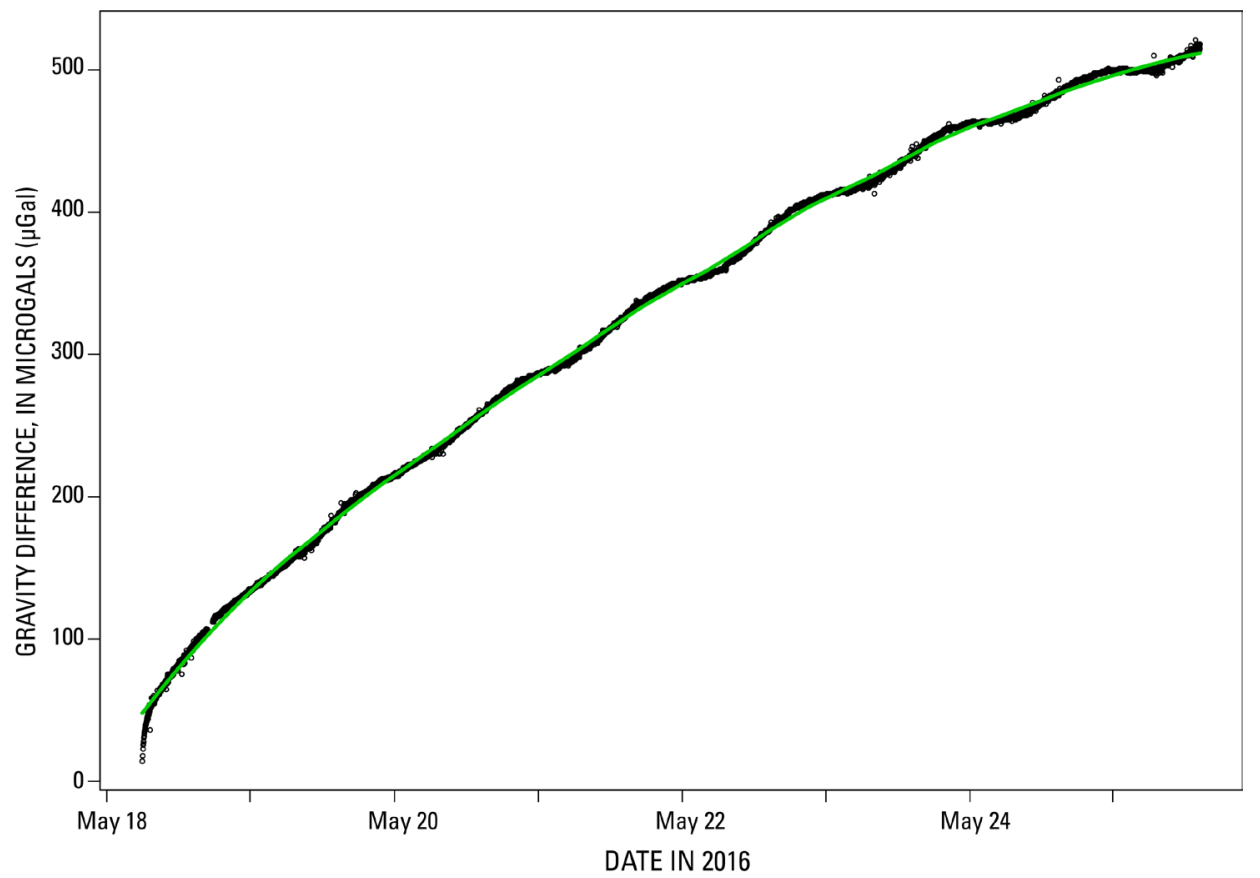

Figure 5. Graph of gravimetric data collected from continuous base station CG5D (fig. 4) over the survey period (small circles) and locally weighted regression curve (green line) fitted to drift component of data. Primary tidal correction has already been applied by using the built-in correction, and approximate initial reading of relative gravimeter $(3,584.9 \mu \mathrm{Gal})$ was subtracted from data to center data points near zero. Note that although model does not fit the first couple of hours of data, this discrepancy is not significant because it precedes time of roving data collection. 


\section{Data Processing}

\section{Modifications to Standard Corrections}

Woolf (2013) used a linear drift correction to account for instrument drift and tidal effects, with a standard value of -308.6 microGals per meter $(\mu \mathrm{Gal} / \mathrm{m})$ of elevation to correct for any observed elevation changes at the stations. In our analysis, we used the following methods:

1. Apply the primary tidal correction, using the formula of Longman (1959).

2. Apply the secondary tidal correction based on the signal observed at the continuous base station.

3. Model the drift rate as a single linear function for the entire day, based on several repeat measurements. The residuals from the linear function are considered to be part of the random measurement error. Standard drift-correction methods assume linear change between successive repeat measurements, resulting in a piece-wise linear function, which does not account for any measurement error. In this report, we apply a single linear correction for the day, derived from the median drift rate, in an attempt to average out the measurement error.

4. Because adequate elevation observations were unavailable for this report, free-air and simple Bouguer anomalies were not calculated, and changes in the gravitational differences from the reference station are assumed to be due solely to mass decreases.

\section{Correction for Secondary Tidal Acceleration}

Secondary tidal accelerations are tidal effects that are not accounted for when using the tidalacceleration corrections described by Longman (1959). These secondary accelerations include local deviations from Longman's formula and accelerations due to ocean loading (deformation of the Earth's crust in response to ocean tides). These accelerations may be corrected for by characterizing them with a static gravimeter base station that records continuously while the roving gravimeter collects the field data (Scintrex, 2006), and subtracting them from the roving gravimeter data. We assume that these secondary tidal accelerations are regional and affect both instruments equally, although the instruments are separated by a distance of $\sim 65 \mathrm{~km}$.

An ideal gravimeter would not give readings that drift over time. However, because the Scintrex CG5 gravimeters use a quartz spring, the spring stretches over time, causing the measurements to drift in an approximately linear fashion over a period of several years (Scintrex, 2006), so that continuous readings taken in the same location will gradually drift because of the properties of the quartz spring unique to that particular gravimeter. Scintrex CG5 gravimeters can be calibrated to adjust for this effect, but the adjustment is imperfect. This instrument drift must be removed before the secondary tidal signal can be modeled and used to adjust from the roving gravimeter data.

The primary tidal accelerations have already been removed from the data plotted in figure 5, leaving only instrument drift, secondary tidal accelerations, and minor accelerations from other ground disturbances (earthquakes, manmade ground shocks, and so on). The approximate initial base reading of the relative gravimeter, 3,584.9, was subtracted from the data to center it near zero. A drastic change in values on the first day of the survey is visible, leveling off to an approximately linear drift for the rest of the survey. The cause of this change in drift is uncertain but may be due to the instrument adjusting to an abrupt change in the local gravitational field caused by transport to a distant field site (Ruedlink and others, 2014). Superimposed on this multiday trend is a cyclic variation with a diurnal period that represents the secondary-tidal-acceleration signal and other minor variations that are assumed to be noise. The instrument drift, secondary tidal signals, and noise differ enough that separating them is relatively straightforward. 
The gravimeter drift at the continuous base station was modeled using a locally weighted regression (Cleveland, 1993) of degree 2 and span 0.3 (green line, fig. 5), where "span" refers to the regression window size and describes the percentage of data used. Thus, a span of 0.3 uses 30 percent of the data centered (that is, \pm 15 percent) at each estimation point. A locally weighted regression was used because the instrument drift subtly deviates from a single polynomial function, and neither linear nor quadratic models adequately captured the drift. The locally weighted regression parameters provided a good fit to the drift without including the significant secondary tidal accelerations. The readings at the continuous base station readings after the drift model is removed are plotted in figure 6 . The daily oscillations in secondary tidal accelerations are clearly visible, as well as the settling-in period of the instrument on the first day.

The secondary tidal accelerations were then modeled using another locally weighted regression of degree 2 and span 0.1 . The small span was required to model the tight curves present in the data. The residuals in the data after subtracting the second locally weighted regression are plotted in figure 7 . The standard deviation of the residuals is \pm 1.2 microGals ( $\mu \mathrm{Gal})$, reinforcing the assumption that all significant tidal accelerations have been accounted for by using the two locally weighted regression models.

The secondary tidal accelerations oscillate between about $\pm 5 \mu \mathrm{Gal}$ (fig. 6 ). Thus characterized, the secondary tidal accelerations can be subtracted from the repeat station data according to the equation

$$
G_{T}=G_{m}-T_{s}
$$

where

$$
\begin{array}{ll}
G_{\mathrm{T}} & \text { is the tidally corrected gravity measurement (primary and secondary tidal effects), } \\
G_{\mathrm{m}} & \text { is the original measurement (already corrected for primary tidal accelerations using } \\
& \text { Longman's formula), and } \\
T_{\mathrm{s}} & \begin{array}{l}
\text { is the secondary tidal correction (estimated using a locally weighted regression } \\
\text { model). }
\end{array}
\end{array}
$$

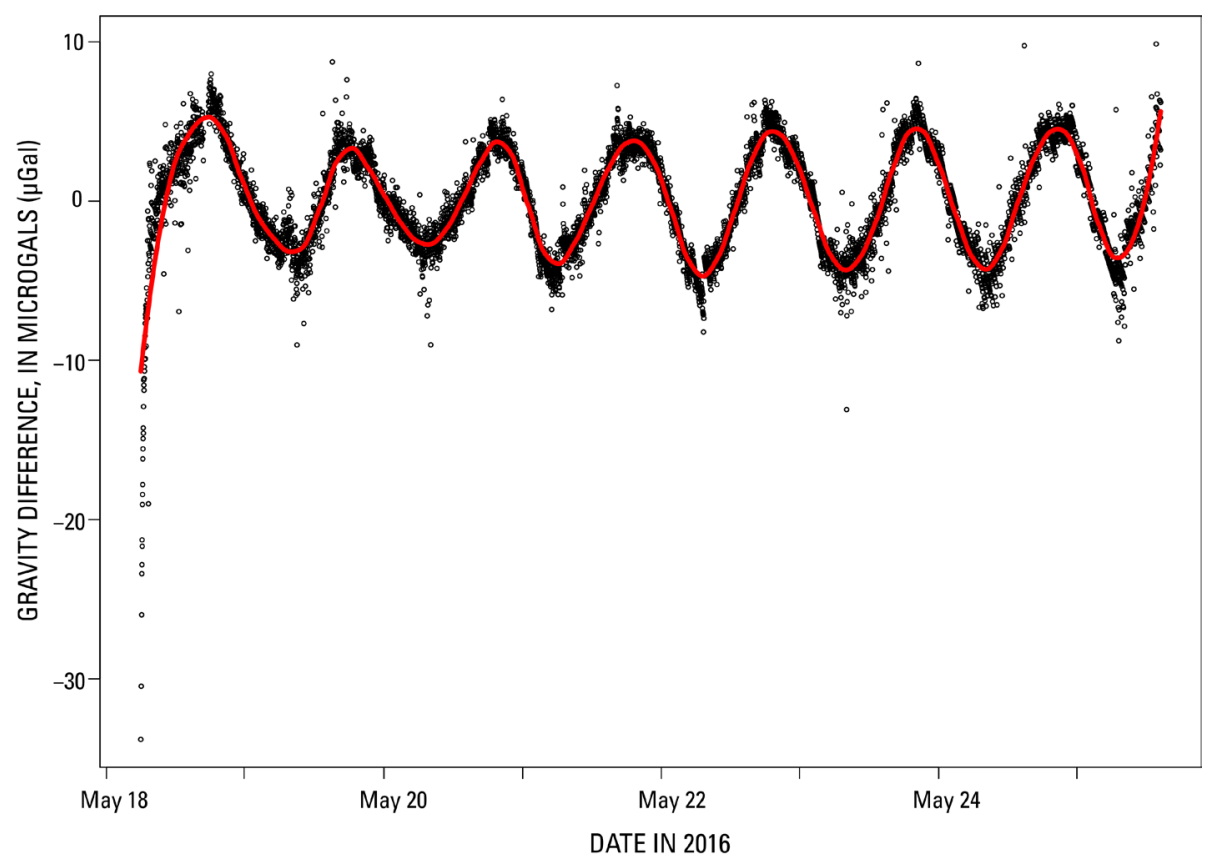

Figure 6. Graph of gravimetric data residuals (small circles) collected from continuous base station CG5D over survey period after removal of effects of instrument drift, showing periodicity of secondary tidal accelerations. $A$ second locally weighted regression curve (red line) has been fitted to the residuals. 


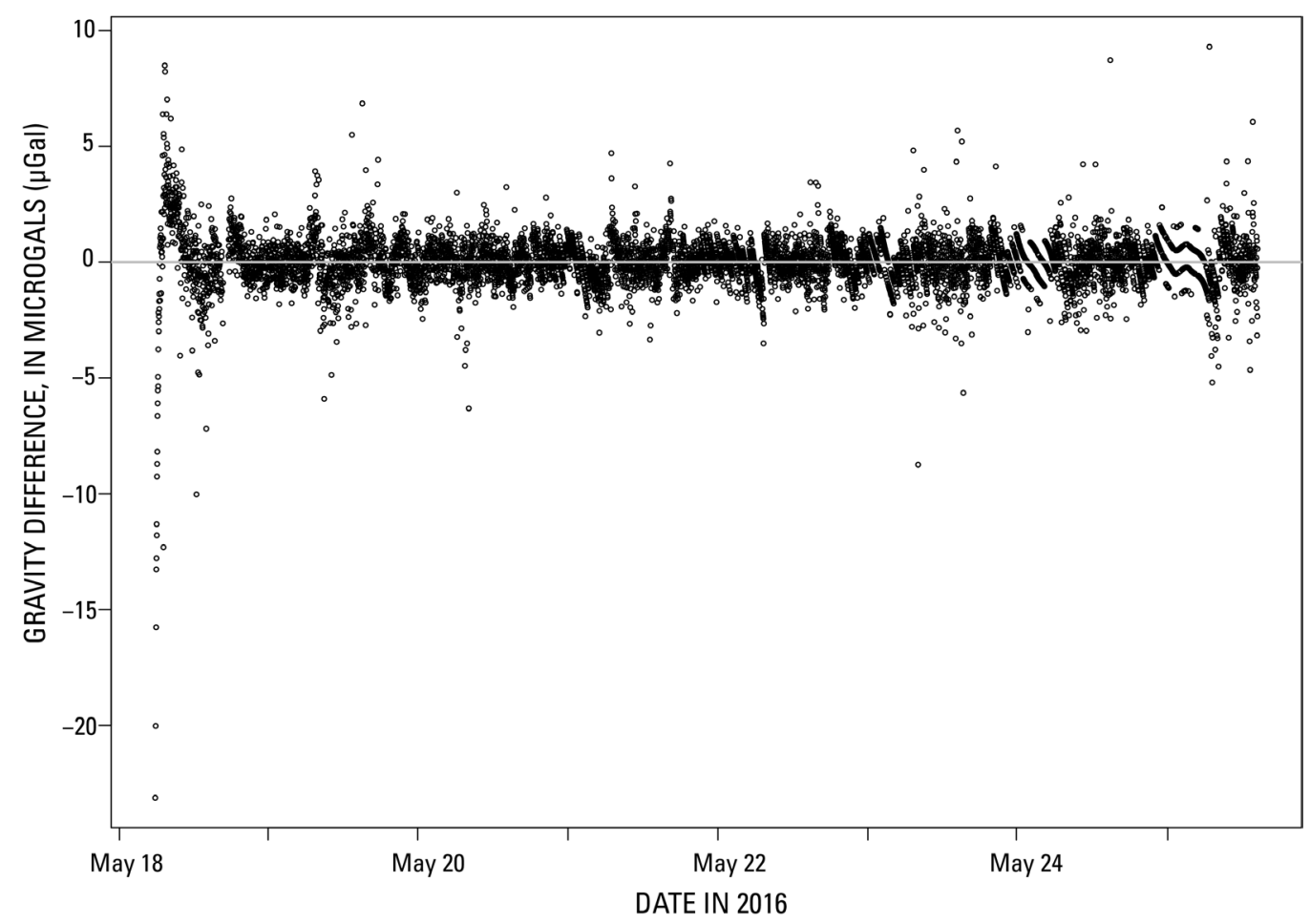

Figure 7. Graph of gravimetric data residuals (small circles) collected from continuous base station CG5D over survey period after removal of effects of instrument drift and secondary tidal acceleration.

\section{Linear Daily Correction Based on Repeat Stations}

The complete nonlinear drift of the roving gravimeter cannot be measured while conducting a survey because it requires measuring in the same location repeatedly (for example, every few minutes). The drift of the roving gravimeter will be more severe than that observed in the gravimeter at the continuous base station because Scintrex CG5 gravimeters are quite susceptible to bias if they are offlevel. Reudlink and others (2014) characterized this problem using several Scintrex CG5 gravimeters; they observed that if a gravimeter was offlevel by $>6^{\circ}$ for a few minutes, the reading bias was tens of $\mu \mathrm{Gal}$, with a maximum of $>100 \mu \mathrm{Gal}$. They noted that the gravimeters took a factor of $\sim 10$ longer than the offlevel time to stabilize; if a gravimeter is transported $>6^{\circ}$ offlevel for an hour, $\sim 10$ hours with the gravimeter stable and level are required for it to recover to normal operating mode. In a typical survey, where the roving gravimeter is transported in the vehicle between stations, the offlevel time of the instrument can be significant, and the resulting nonlinear pattern of bias and recovery would potentially be quite complex. Furthermore, Reudlink and others (2014) determined that this effect varies in magnitude from one instrument to another. In addition to the bias owing to instrument tilt, noise is also added to the measurement as the roving gravimeter is subjected to changes in temperature, decreasing battery voltage throughout the day, and so on.

Although the nonlinear drift function cannot be characterized for the roving gravimeter, the daily linear component of that drift can be characterized by measurements at repeat stations over the course of the survey.

Ideally, a single repeat station would be chosen, which would be measured on a regular basis throughout the survey. Common recommendations are to repeat the measurement every 2 hours (Dobrin and Savit, 1988; Lowrie, 1993). In practice, however, this routine is rarely feasible for logistical reasons. Commonly, stations are too far apart to reach the repeat station regularly, or even at all, during 
a given survey day. Therefore, repeat measurements are made at convenient locations throughout the survey day. For example, on returning down a road where measurements were just taken, every tenth measurement might be repeated. Access points to the survey area also are generally convenient for repeat measurements. A repeat station should be checked at least every 2 hours if at all possible. The more repeat stations that are checked throughout the day, the better the characterization of the daily instrumental drift.

For our survey, two pairs of repeat measurements were taken at the beginning and end of each day, and measurements were repeated elsewhere throughout the survey when convenient. At the beginning of each survey day, a measurement was taken at the GPO (gravity station GPOBASE), a 45minute drive from the survey area. After traveling to the survey area, a measurement was taken at the reference station CS25. The process was repeated in reverse order at the end of each survey day. Together, these data provide two estimates of the linear component of daily instrument drift. These measurements are plotted in figure 8, with the mean of each station (GPOBASE and CS25) subtracted from their respective group so that both station measurements plot near zero and the pattern of daily station fluctuations can be compared.

The measurements at station GPOBASE show a regular pattern (fig. 8): an average drift of about $-50 \mu \mathrm{Gal}$ during the day, which is recovered by an average drift of about $+50 \mu \mathrm{Gal}$ overnight, with a possible tare of about $+100 \mu \mathrm{Gal}$ overnight after day 1 . If these were the only data available, we might think that the gravimeter was behaving consistently. However, the measurements at station CS25, which bracket the survey data in time more closely than those at station GPOBASE, do not show the same regularity. In fact, on survey days 6 and 7, the measurements at station CS25 contradict those at station GPOBASE, implying very little drift over most of the survey day. This inconsistent behavior between repeat measurements indicates nonlinear drift, which cannot be well characterized in field settings. Furthermore, gravimeters appear to drift at different rates from day to day, and so the drift function from one day cannot be expected to apply to other days. However, the linear component of the drift can be estimated and removed by using multiple repeat measurements and calculating a median drift rate for each day.

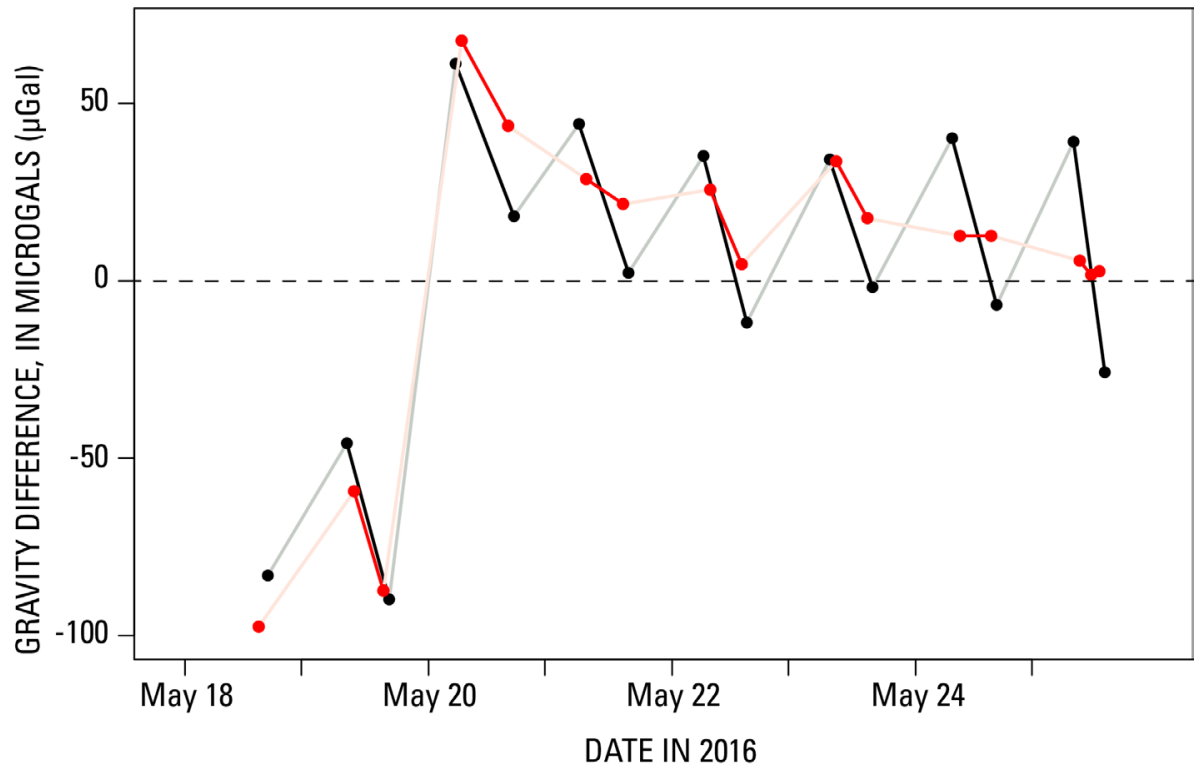

Figure 8. Graph of apparent linear instrument drift of roving gravimeter at repeat station GPOBASE (black) and reference station CS25 (red). Black and red lines connect daily readings, light-gray and pink lines connect overnight readings. Measurements have been centered by subtracting their respective mean. Note that true drift between data points is nonlinear; connecting lines are linear approximations. 
The drift rate, the change in measurement over a given period of time, can be linearly approximated by taking repeat measurements over the course of each survey day. After the primary and secondary tidal effects have been accounted for, the apparent drift rate $\left(D_{\text {apparent }}\right)$ for a given time interval can be calculated by the difference in gravity divided by the difference in time for each pair of repeat measurements:

$$
D_{\text {apparent }}=\left(\frac{G_{\mathrm{Tf}}-G_{\mathrm{Ti}}}{t_{\mathrm{f}}-t_{i}}\right)
$$

where $G_{\mathrm{T}}$ is the tide-corrected gravity, $t$ is time, and subscripts $\mathrm{f}$ and $\mathrm{i}$ indicate final and initial measurements, respectively. The apparent drift rate is then paired with the midpoint of the time window. The apparent drift rate for repeat measurements taken within a given survey day is plotted in figure 9 .

For any given day, several apparent drift rates are evident. Typically, at least five pairs of readings are available. The median of these drift rates was chosen to represent the linear drift rate for each survey day (Sen, 1968), and a correction was applied to the data for that day on the basis of this linear drift rate. The first measurement at reference station CS25 each day was defined as time zero, and all corrections were made relative to this:

$$
G_{\text {adj }}=G_{\mathrm{T}}-D_{\mathrm{a}}\left(t-t_{\mathrm{CS} 25}\right),
$$

where

$$
\begin{aligned}
G_{\text {adj }} & \text { is the gravity data adjusted for the primary and secondary tidal corrections and } \\
& \text { instrument drift, } \\
G_{\mathrm{T}} & \text { is the tide-corrected (primary and secondary) gravity measurement (see eq. 2), } \\
D_{\mathrm{a}} & \text { is the linear drift rate (median of the drift rates), } \\
t & \text { is the time of measurement, and } \\
t_{\mathrm{CS} 25} & \text { is the time of the morning measurement at reference station CS25. }
\end{aligned}
$$

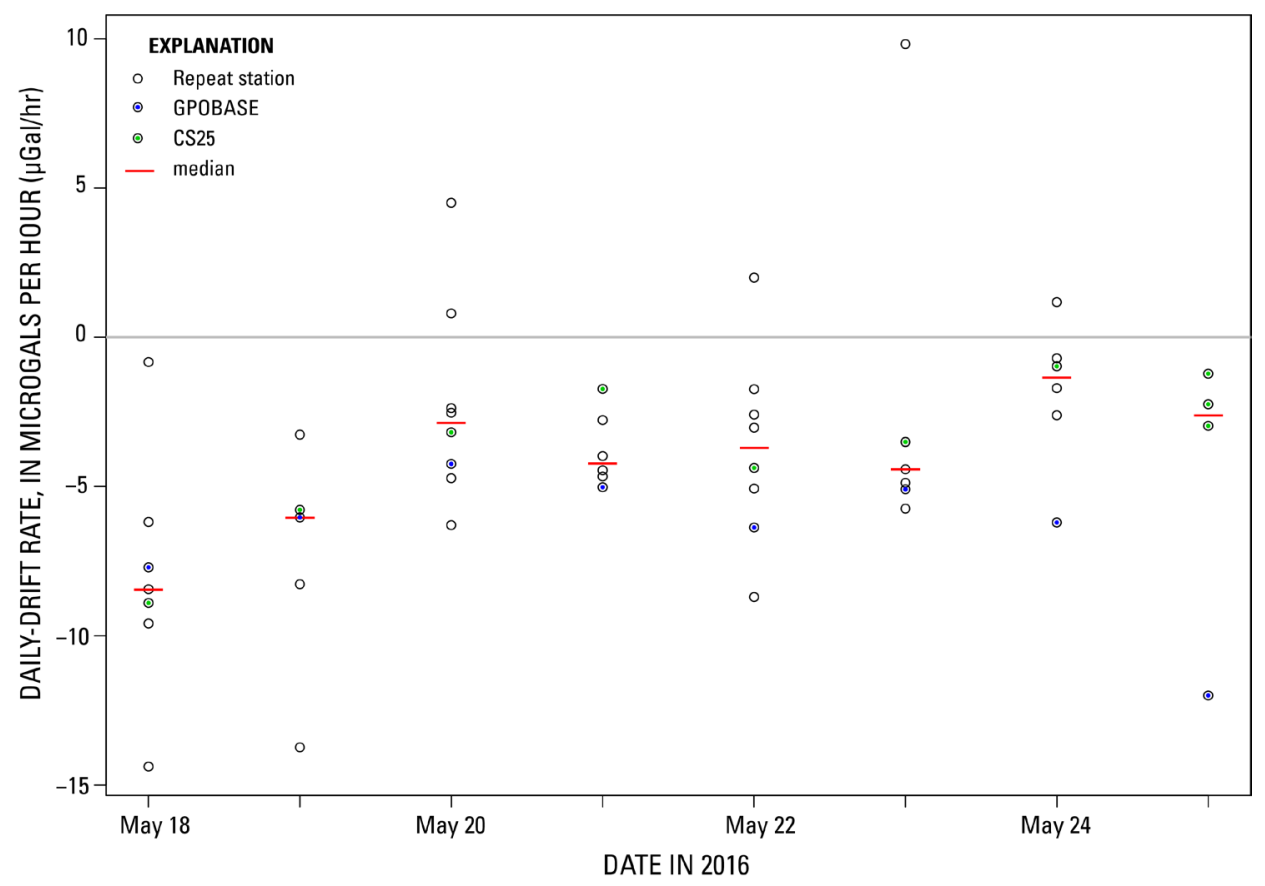

Figure 9. Graph of apparent daily-drift rate (small circles) for measurement pairs at all repeat gravity stations where both measurements were taken on the same day, and for repeat station GPOBASE (blue circle) and reference station CS25 (green circle). Red lines denote median drift rates used for correcting for daily drift rate. 
The pairwise differences between repeat measurements at a given station can be used to estimate the measurement uncertainty. Pairwise differences are calculated by taking the difference of all combinations of measurements at a given station on a given day. If instrument drift has affected the measurements, then these pairwise differences will be larger than if the effect of the drift was removed. After adjusting the data for the linear component of drift, the distribution of pairwise differences for all repeat measurements is centered on zero and has a standard deviation of $\pm 13 \mu \mathrm{Gal}$ (fig. 10). This result can be compared with the differences in repeat measurements before removing the linear component of drift; note that these differences are negatively biased (median is $-17 \mu \mathrm{Gal}$ ) and have a larger spread of values (standard deviation is $\pm 24 \mu \mathrm{Gal}$ ), consistent with the negative drift rate observed during the day. The drift correction has centered and reduced the variance of the measurement uncertainty.

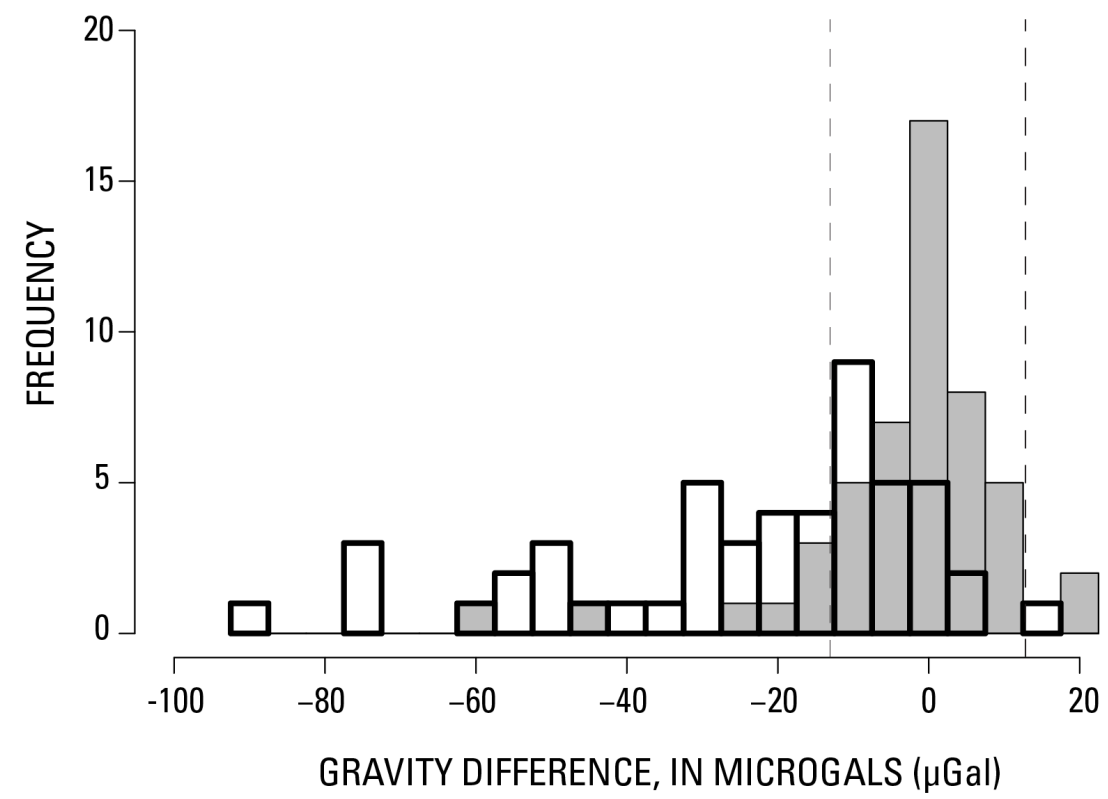

Figure 10. Histogram of gravity differences between repeat measurements before within-day drift correction (bold black-outlined areas) and after daily-drift correction (grey-filled areas). Dashed lines (at \pm 13 microGals, $\mu$ Gal) show the standard deviation of drift-corrected differences.

\section{Elevation Correction}

Differences in the gravity at a given station over time can be caused by changes in elevation (for example, ground subsidence or uplift). The free-air and simple Bouguer corrections are applied to gravity data to account for both distance and mass above sea level (Blakely, 1995). The elevation correction is approximately -0.197 milliGals per meter $(\mathrm{mGal} / \mathrm{m})$ of elevation above sea level (assuming a standard reduction density of 2,670 kilograms per meter cubed, $\mathrm{kg} / \mathrm{m}^{3}$ ), or +1.97 microGals per centimeter $(\mu \mathrm{Gal} / \mathrm{cm})$ of elevation decrease (subsidence). A correction for any change in elevation should be applied to the data before comparing with previous values.

Because the elevation data at the stations measured in 2016 were unavailable, an assessment of elevation change could not be made for this survey. However, the Scripps Orbit and Permanent Array Center (SOPAC) dataset lists a permanent GPS station south of the Coso geothermal field (fig. 1) that shows a subsidence of 4.4 millimeters (mm) from 1995 to 2015. Additionally, InSAR investigations show subsidence over the Coso geothermal field. Fialko and Simons (2000) estimated a subsidence rate of $\sim 3.5$ millimeters per year (mm/yr) from 1993 to 1999, and Ali and others (2016) calculated a slightly lower rate of $\sim 2.5 \mathrm{~mm} / \mathrm{yr}$ from 2004 to 2011 , suggesting that the elevation changes in the Coso geothermal field are related to subsidence rather than to uplift. 
Because subsidence adds positively to the gravity anomaly, if subsidence at a given gravity station had been accounted for, it would have caused the modeled water table to be higher than actual. The reverse is true for an uplift in elevation. Assuming subsidence only, the elevation of the modeled water table in this report is therefore a maximum.

\section{Datum Shift to Reference Station CS25}

So far, the data have been adjusted for tidal accelerations, instrument drift, and elevation changes, although in our survey we lacked elevation data, and so the correction for elevation was zero. Both the previous and new data must still be shifted to a common datum. Previous data were shifted to the station CS25 datum because of its stability as a reference station. Data collected from 1991 to 2003 were shifted to the station CS25 datum by subtracting the value at station CS25 in each survey from the rest of the dataset. The 2016 survey data were shifted to the survey's daily median value at station CS25. To obtain a single value for repeat gravity stations (which have several measured values), these stations were assigned the median value. The dataset for the 2016 survey contains a single value for each gravity station, obtained by the previously described processing method. Each gravity value is measured relative to station CS25. These relative gravity values differ from the observed gravity values by a constant, the absolute gravity value at station CS25. Because our survey was concerned only with the differences in gravity, the observed gravity value need not be calculated. The relative gravity is given by

$$
G_{\mathrm{R}}=G_{\text {adj }}-1.97 h-G_{\text {adj_CS} 25}
$$

where

$G_{\mathrm{R}} \quad$ is the relative gravity,

$G_{\text {adj }} \quad$ is the adjusted gravity data (see eq. 3),

$h \quad$ is the elevation change (in $\mathrm{cm}$, negative for subsidence, positive for uplift), and

$G_{\text {adj_CS25 }} \quad$ is the adjusted gravity value at station CS25.

Two things should be noted in equation 4: (1) for our survey, elevation data were not available, and so $h$ was set to zero for all measurements; and (2) equation 4 assumes that the elevation of station CS25 has not changed. In the case of a change in elevation at CS25, an additional elevation term would need to be added. All relative gravity values are given in table 1 at the end of this report.

\section{Data Processing Summary}

The data-processing steps are summarized as follows:

1. Acquire continuous-base-station and roving data directly from Scintrex CG5 gravimeters; measurements should include all built-in Scintrex corrections, including calibrated drift correction, tidal acceleration correction using Longman's (1959) formula, frequency filtering, and so on.

2. Process continuous-base-station data.

A. Apply correction for multiday drift in the continuous base station.

B. Characterize the secondary tidal acceleration signal by analyzing the data from the continuous base station.

3. Process rover data.

A. Apply correction for secondary tidal acceleration (derived from the continuous base station).

B. Calculate the apparent drift rate for all combinations of repeat station signals. 
C. Characterize and apply the daily drift by using the median daily drift rate (Sen's [1968] method).

D. Adjust for changes in station elevation over time $(+1.97 \mu \mathrm{Gal} / \mathrm{cm}$ of subsidence).

E. Shift previous data so that they are relative to station CS25 to calculate the relative gravity.

After the data have been corrected and adjusted to the same datum, gravity changes over time can be estimated.

\section{Modeling}

To assess the changes in free-water level since 1991, the processed gravity values from our survey were subtracted from those of each of the previous surveys. The change can then be modeled from these gravity differences. Processed time-lapse gravity data from 1991 through 2013 show that a negative gravity anomaly has been present and increasing in magnitude over the Coso geothermal field for the past 2 decades.

The modeling is complicated somewhat by missing data. In previous years, some gravity stations were not measured, and for some years no data were collected at all. The first year when the measured stations matched those that were measured in 2016 was in 1996. (Only two stations were different between the datasets.) We therefore used the difference between the spring 1996 gravity dataset and the spring 2016 gravity dataset to estimate the water-table drawdown. Two missing measurements from the 1996 dataset are from stations RE12 and RE15 (fig. 3); station RE12 was not measured, and station RE15 has a data-entry error. (The recorded value is an order of magnitude higher than from all other stations and the values from station RE15 for all other years).

Woolf (2013) described the processing of data from the 1996 survey. The data were corrected for daily drift and tidal effects, leveled from reference station J4 to reference station B14 (fig. 3), and corrected for elevation changes using real-time kinematic elevation data. This description, however, is rather limited, and such details as how the drift correction was calculated and applied, how the tidal effects were calculated and applied, and what formulas were used for the elevation correction are unavailable.

The time-lapse difference in gravity between 1996 and 2016 is mapped in figure 11. A conspicuous negative gravity anomaly is centered on stations CER1 and RE4 (fig. 3), which record gravity anomalies of -315 and $-294 \mu \mathrm{Gal}$, respectively. The overall shape of the gravity anomaly resembles the drawdown cone of a water table due to well pumping. The trend in the time-lapse gravity anomaly for station CER1, from 1991 to present, is shown in figure 12.

The change in gravity over time was modeled as a drop in the water table by assuming that the decrease in gravity was due to the decrease in mass associated with years of geothermal production, as the rocks changed from saturated to unsaturated. This approach was also taken by Woolf (2013). Woolf (2013) assumed (1) constant porosity over time, (2) a fluid density of 1 gram per cubic centimeter $\left(\mathrm{g} / \mathrm{cm}^{3}\right),(3)$ a negligible gas density $\left(0 \mathrm{~g} / \mathrm{cm}^{3}\right)$, and (4) a rock-porosity saturation of 100 percent (either entirely gas or entirely liquid). They reported porosity of 5-10 percent, resulting in a density contrast of 0.05 to $0.2 \mathrm{~g} / \mathrm{cm}^{3}$ between saturated and unsaturated rocks. They further assumed an original static water level of $762 \mathrm{~m}$ (2,500 feet) above sea level. In this report, we maintain these assumptions. We also assume that the negative gravity anomaly over the Coso geothermal field is due entirely to drawdown of a single water table beneath the geothermal field. 


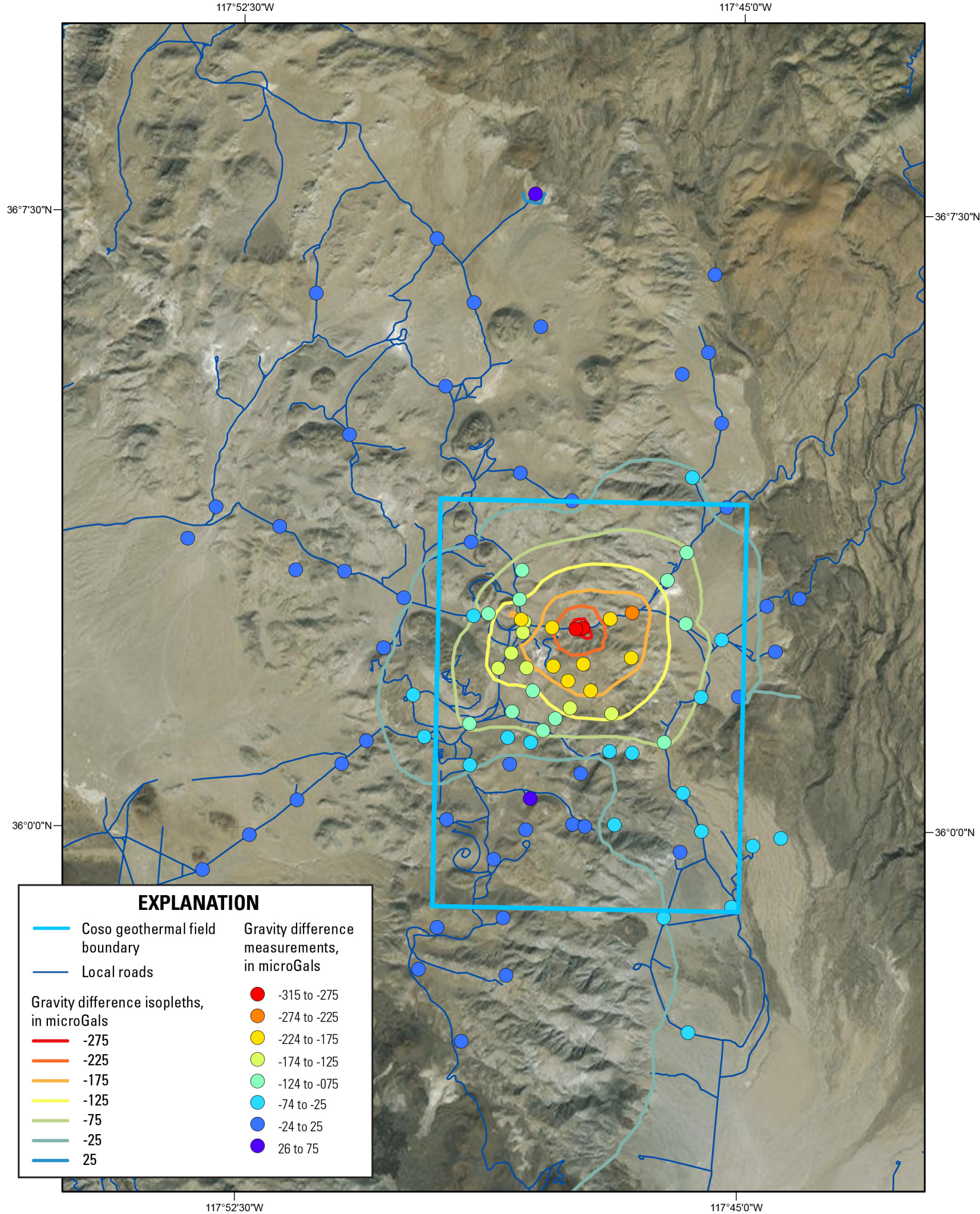

Figure 11. Map of gravity differences from 1996 to 2016 measured at gravity stations in the vicinity of the Coso geothermal field in the Coso Basin, south-central California. Map imagery from Esri (2017) and its licensures. 
The depth of water drawdown was estimated by calculating the negative gravity anomaly produced by vertical rectangular prisms whose density is less than that of the water-saturated rocks below them. The prisms were defined to be $100 \mathrm{~m}$ on a side, with height allowed to vary in order to fit the gravitational anomaly. Prism heights were grouped according to the nearest gravity station, and the heights of all prisms in the same group are the same. The prism groups effectively form Thiessen polygons across the study area, with one gravity station located at the center of each polygon (fig. 13). The height of the prism within each Thiessen polygon is constant, and the resulting model therefore has a "stairstep" pattern. Such an approach was taken because it is simple and requires few assumptions. It produces a reasonable model that fits the data and illustrates the approximate nature of the resulting solution.

The modeling proceeded as follows:

1. Estimate the depth (height) of unsaturated rocks beneath each gravity station by applying the infinite-slab formula (Telford, 1976) to the gravity anomaly, and set the prism depths to these values. This formula will underestimate the depth needed to generate the same anomaly in a finite model (such as the one used in this report). Because this formula underestimates the depth, iterative use of the formula results in convergence. The same approach was taken by Bott (1960) and Jachens and Moring (1981).

2. Calculate the gravitational effect of the prisms on the gravity stations.

3. Subtract the calculated gravitational effect from the measured gravity anomaly to yield a residual anomaly.

4. If the difference between the measured gravity anomaly and the calculated gravitational effect is $<26 \mu \mathrm{Gal}$ (the estimated precision of the 2016 data to two standard deviations), stop growing the prisms; otherwise, proceed to step (1) using the residual gravity anomaly.

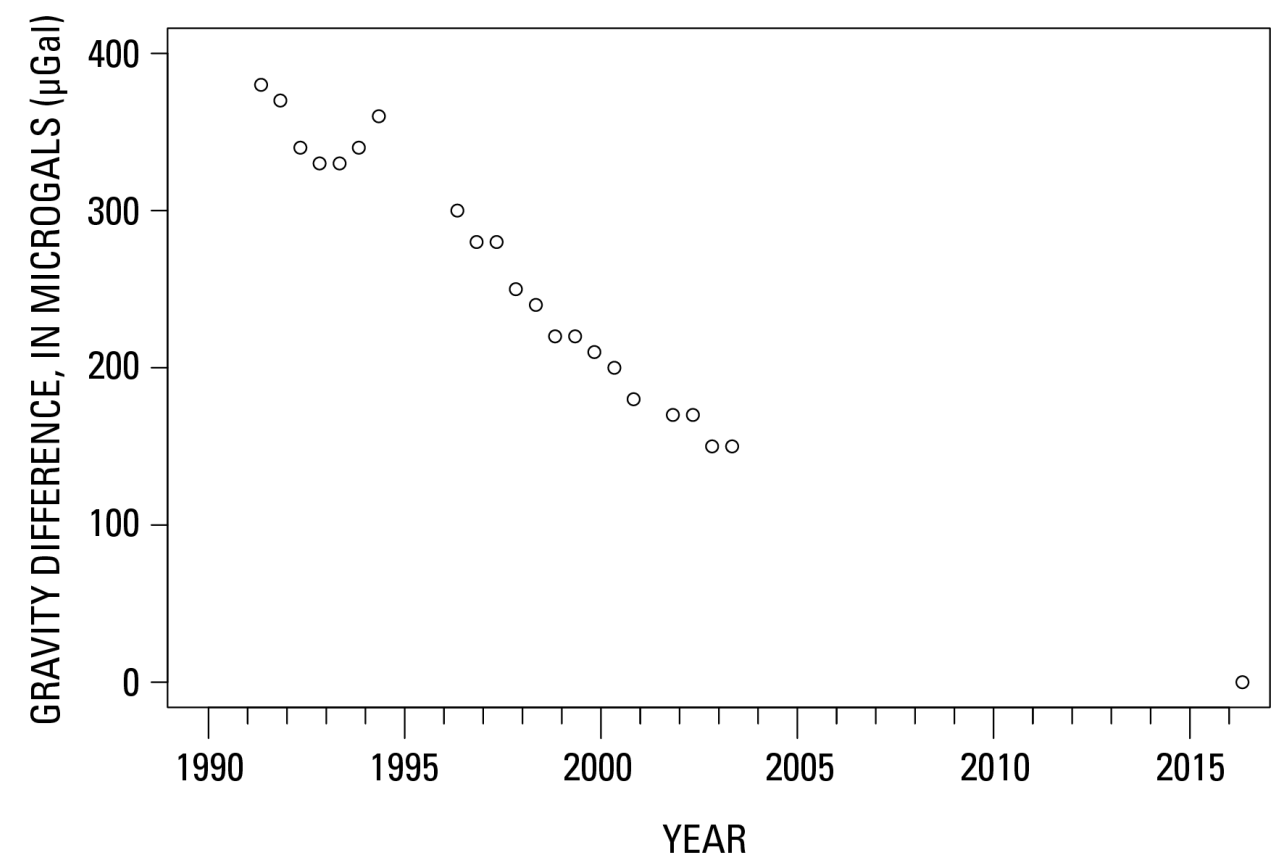

Figure 12. Graph of gravity differences from 1996 to 2016 measured at station CER1, showing decrease in relative gravity over time, with 2016 value normalized to zero. 


\section{Results}

\section{Model Results}

Two models of mass decline were generated (fig. 13), one using a density contrast of $0.05 \mathrm{~g} / \mathrm{cm}^{3}$ (model 0.05 ) and one using a density contrast of $0.2 \mathrm{~g} / \mathrm{cm}^{3}$ (model 0.2 ), the lowest and highest density contrasts deemed reasonable by Woolf (2013). Both models predict a quasi-circular anomaly $\sim 4 \mathrm{~km}$ across, with the greatest drawdowns associated with gravity stations CER1 and RE4 (fig. 3). The adjacent surrounding drawdowns are about two-thirds of the greatest depth, and the rest of the model shows only minor drawdown, indicating that drawdown is localized near these two stations.

The (minimum) depth of water-table decline predicted by each model is strongly influenced by the chosen density contrast. At a density contrast of $0.2 \mathrm{~g} / \mathrm{cm}^{3}$, the maximum predicted drawdown is 65 $\mathrm{m}$; and at a density contrast of $0.05 \mathrm{~g} / \mathrm{cm}^{3}$, the maximum predicted drawdown is $326 \mathrm{~m}$. The shapes of the models are nearly identical; only the predicted drawdowns differ appreciably. The density contrast is likely the single most important variable in modeling because it has the largest effect on the predicted depth of drawdown, in this case changing the estimated drawdown by a factor of 5.

The two models fit the measured gravity anomaly remarkably closely. The model using a density contrast of $0.05 \mathrm{~g} / \mathrm{cm}^{3}$ deviates from the measured gravity anomaly by a minimum and maximum misfit of -40 and $65 \mu \mathrm{Gal}$, respectively, and a mean absolute deviation of $11.1 \mu \mathrm{Gal}$ (within one standard deviation of the measurement uncertainty). The model using a density contrast of $0.2 \mathrm{~g} / \mathrm{cm}^{3}$ deviates from the measured gravity anomaly by a minimum and maximum misfit of -40 and $64 \mu \mathrm{Gal}$, respectively, and a mean absolute deviation of $11.1 \mu \mathrm{Gal}$. Figure 14 shows the modeled surface from two angles, south and southeast, with the modeled surface intersecting the measured gravity anomaly from identical angles, showing that the overall model fit to the central gravity anomaly is reasonable.

An interesting result of our survey is the small-magnitude but widespread decrease in gravity relative to 1996 in the southeast corner of the study area (fig. 11). This small decrease could indicate a local water-table lowering in the northernmost part of the Coso Basin (southeast corner of study area). 


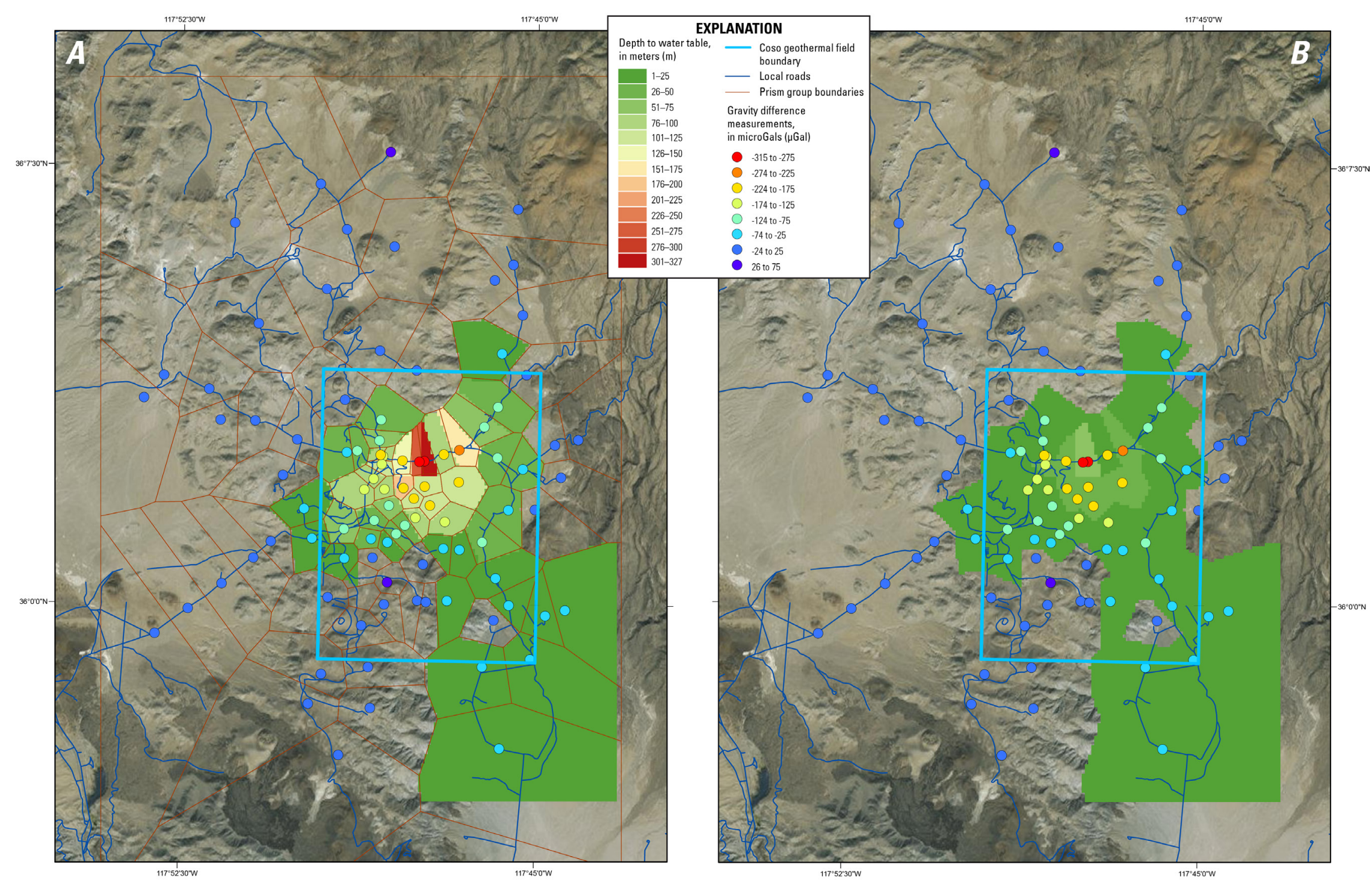

Figure 13. Map of modeled water-table drawdown for saturated/unsaturated density contrasts of 0.05 grams per cubic centimeter $\left(\mathrm{g} / \mathrm{cm}^{3}\right)(A)$ and $0.2 \mathrm{~g} / \mathrm{cm}^{3}(B)$ in the Coso Basin, south-central California. Thiessen polygons in $A$ bound the modeled groups of prisms of equal height. Map imagery from Esri (2017) and its licensures. 

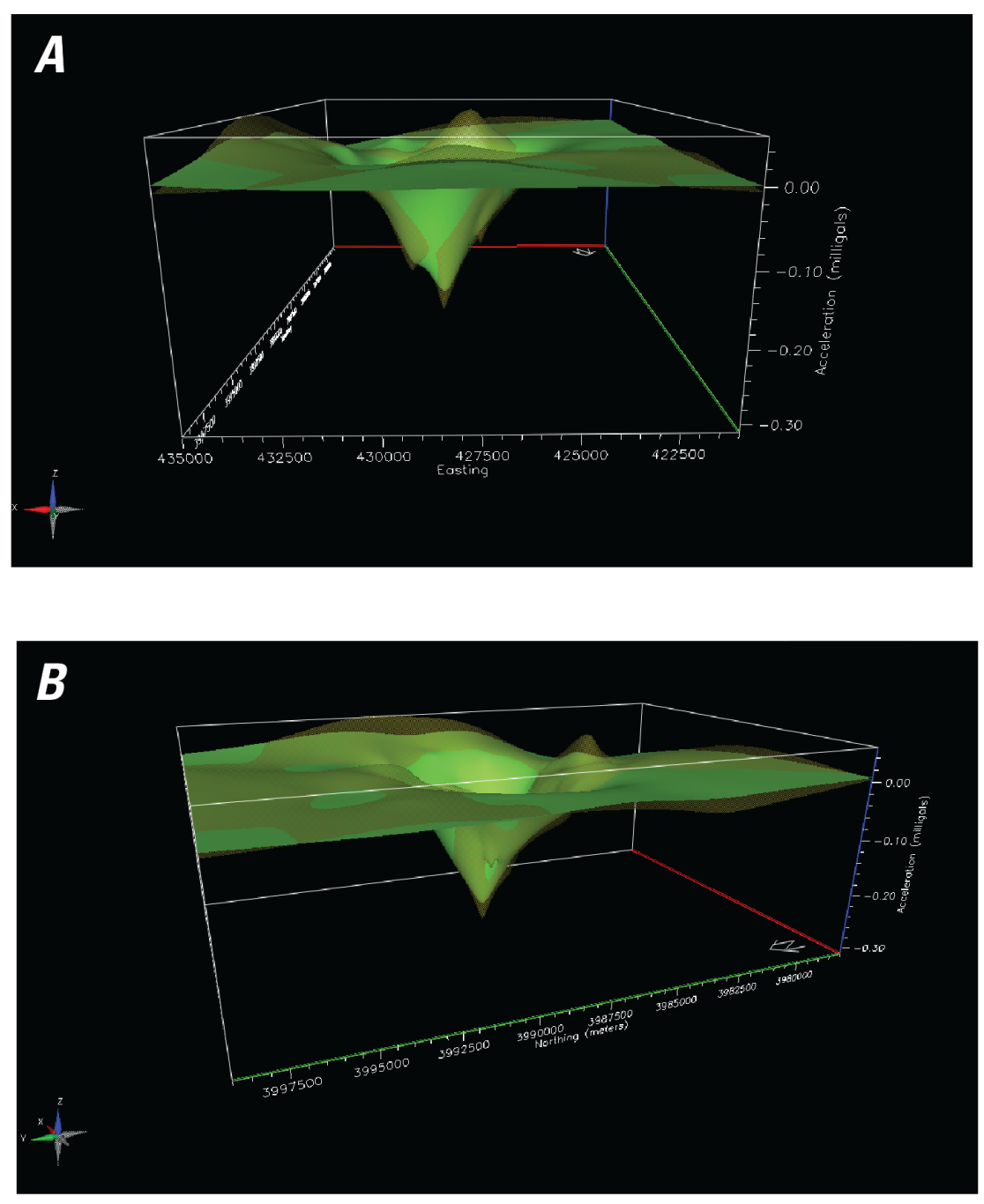

Figure 14. Three-dimensional plot of the calculated gravity anomaly (green surface) overlain on the measured gravity anomaly (red surface) in the Coso geothermal field in the Coso Basin, south-central California. $A$, View southward. $B$, View southeastward. Surfaces intersect at points where an exact match occurs.

\section{Model Uncertainty}

Many factors contribute to uncertainty in the modeling. Although quantifying the sources of uncertainty is beyond the scope of this report, several contributing factors should be mentioned.

1. Because subsidence data are missing, we have assumed that the modeled gravity anomaly is due entirely to mass removal, although this is not necessarily the case. If free-water levels are dropping, this decline may very well be accompanied by subsidence. Correcting for subsidence increases the magnitude of a negative gravity anomaly caused by water-table drawdown, which would cause a deepening in the estimated drawdown.

2. The elevation of the water table in 1996 is unknown and has been nominally placed at $762 \mathrm{~m}$ above sea level (2,500 feet), following the previous assumptions of Woolf (2013). 
3. Third, the density contrast between saturated and unsaturated rocks is unknown and is probably variable rather than constant, depending on rock type, rock porosity, fluid density, and degree of saturation. Increasing the density contrast decreases the estimated drawdown; conversely, decreasing the density contrast increases the estimated drawdown, which tends toward infinity as the density contrast approaches zero.

4. Any mass change owing to mineral dissolution and transport has not been captured here.

The measurement uncertainty in previous data is undocumented. If the previous data have an uncertainty similar to that of data collected in our survey, then differencing the surveys would raise the standard deviation from $13 \mu \mathrm{Gal}$ to $\sim 18 \mu \mathrm{Gal}$, assuming that measurement errors are uncorrelated. This estimate is likely conservative because there is no indication that previous surveys modeled the secondary tidal effects, estimated in 2016 to have an amplitude of $9 \mu \mathrm{Gal}$, or characterized and subtracted the daily instrument drift - thus, the previous standard deviation is likely to exceed the 2016standard deviation.

\section{Conclusion}

Gravity data collected with a relative gravimeter can be used effectively for time-lapse investigations, with the data collection and processing procedures outlined to minimize random and systematic errors in the dataset. The data processing includes a correction for secondary tidal effects, made possible by using a static gravity base station, and measuring multiple repeat gravity stations to reduce the potentially significant effect of daily instrument drift. In our survey, the estimated standard deviation of the gravity measurements is $\pm 13 \mu \mathrm{Gal}$.

The gravity data reveal a deepening of the negative time-lapse gravity anomaly within the Coso geothermal field, centered near gravity station CER1. The data indicate that this anomaly has gradually increased over the past 2 decades.

Interpreting the gravity anomaly as due solely to a lowering of the water table, the two models presented in this report indicate the water-table drawdown to range from 65 to $326 \mathrm{~m}$ below the assumed original water-table elevation of $762 \mathrm{~m}$. Additionally, a small drawdown is predicted in the southeast corner of the study area, at the north end of the Coso Basin, on the basis of a small but systematic reduction in gravity measured in that area.

Significant uncertainties are associated with the quantitative estimate of drawdown in the study area. However, consistently decreasing gravity and consistent spatial patterns have been observed over the Coso geothermal area, and water-table drawdown is likely a significant factor in generating the ongoing time-lapse gravity anomaly.

Table 1. Location and relative gravity values for stations measured in this study. [Location data are provided in the California State Plane Coordinate System of 1927 (CSS27) Zone 4.]

\begin{tabular}{lccc}
\hline \multicolumn{1}{c}{ Station } & $\mathbf{X}$, in feet & $\mathbf{Y}$, in feet & $\begin{array}{c}\text { Change in gravity } \\
(\Delta \mathbf{G}) \text {, in milliGals }\end{array}$ \\
\hline B-14 & 2346679 & 251644 & 2.2839003 \\
B-15 & 2330512 & 241483 & 37.44722993 \\
CER1 & 2358202 & 259877 & 8.02527586 \\
CER15 & 2353877 & 260288 & -6.1512531 \\
COSO2 & 2330960 & 268320 & 7.19452032 \\
COSO3 & 2349818 & 266094 & -24.87773522 \\
CS1 & 2342409 & 251235 & 29.11036097 \\
CS10 & 2364359 & 251561 & 32.48884178 \\
CS11 & 2365834 & 247856 & 36.65477518
\end{tabular}




\begin{tabular}{|c|c|c|c|}
\hline Station & $X$, in feet & $Y$, in feet & $\begin{array}{l}\text { Change in gravity } \\
(\Delta G) \text {, in milliGals }\end{array}$ \\
\hline $\mathrm{CS} 12$ & 2365708 & 243486 & 55.09576485 \\
\hline CS13 & 2364606 & 238617 & 68.77497728 \\
\hline $\mathrm{CS} 14$ & 2346594 & 234447 & -47.60753397 \\
\hline CS15 & 2347906 & 237574 & -42.18800904 \\
\hline CS16 & 2357741 & 245372 & 5.72716592 \\
\hline CS17 & 2354567 & 247230 & 1.49475769 \\
\hline CS18 & 2360343 & 250819 & 17.82986252 \\
\hline CS19 & 2355426 & 252272 & 7.91335847 \\
\hline CS20 & 2350065 & 249624 & -2.72962794 \\
\hline CS21 & 2350124 & 260639 & -6.34720485 \\
\hline CS22 & 2344933 & 261877 & -4.32993882 \\
\hline $\mathrm{CS} 23$ & 2343537 & 258156 & -0.74916968 \\
\hline $\mathrm{CS} 24$ & 2340551 & 263754 & -12.07534502 \\
\hline $\mathrm{CS} 25$ & 2335681 & 266955 & 0 \\
\hline CS26 & 2328934 & 265923 & 16.30083057 \\
\hline CS28 & 2353345 & 271263 & -48.42762776 \\
\hline CS29 & 2347701 & 277565 & -56.19733996 \\
\hline $\mathrm{CS} 3$ & 2368659 & 269038 & 19.32376791 \\
\hline CS30 & 2349671 & 283786 & -62.05572829 \\
\hline CS31 & 2353638 & 264066 & -17.38258681 \\
\hline CS34 & 2372447 & 258439 & 22.19266726 \\
\hline CS35 & 2369775 & 255063 & 28.58600883 \\
\hline CS36 & 2371084 & 244052 & 56.0681364 \\
\hline CS37 & 2373119 & 244667 & 52.9236494 \\
\hline CS38 & 2369579 & 239487 & 68.25430688 \\
\hline $\mathrm{CS} 4$ & 2368132 & 275242 & -1.58990787 \\
\hline CS41 & 2346863 & 288461 & -64.7217675 \\
\hline CS43 & 2340691 & 273831 & -46.7128235 \\
\hline CS44 & 2338026 & 284231 & -53.85578056 \\
\hline CS5 & 2367032 & 280462 & -20.80573685 \\
\hline CS52 & 2354656 & 282094 & -62.84691893 \\
\hline CS6 & 2366057 & 271193 & 12.18149589 \\
\hline CS63 & 2361998 & 213658 & 97.42615993 \\
\hline CS64 & 2366575 & 230164 & 80.01728066 \\
\hline CS65 & 2367419 & 286210 & -36.10457569 \\
\hline CS66 & 2336949 & 263777 & -10.11209437 \\
\hline CS67 & 2345799 & 254712 & -23.43168683 \\
\hline CS7 & 2365737 & 265643 & 24.23116967 \\
\hline CS70 & 2363225 & 253574 & 25.95837256 \\
\hline CS8 & 2365787 & 260373 & 25.67756685 \\
\hline CS9 & 2367032 & 254975 & 28.70804436 \\
\hline CSE1 & 2355932 & 259877 & 1.34913998 \\
\hline CSE2 & 2356081 & 257042 & -23.3184232 \\
\hline CSE3 & 2358865 & 255279 & 6.15335721 \\
\hline CSE4 & 2361824 & 257774 & 8.48845744 \\
\hline CSE5 & 2358266 & 249140 & 16.85578651 \\
\hline CW1B & 2364362 & 263550 & 23.83963851 \\
\hline DOR37 & 2368460 & 259243 & 26.65109478 \\
\hline DOR38 & 2371730 & 261803 & 20.26332768 \\
\hline DOR39 & 2374136 & 262389 & 5.84190669 \\
\hline DOR64 & 2333920 & 244121 & 31.40327054 \\
\hline DOR65 & 2337374 & 246758 & 29.03973491 \\
\hline DOR66 & 2340631 & 249514 & 31.51190039 \\
\hline
\end{tabular}




\begin{tabular}{lrrc}
\hline \multicolumn{1}{c}{ Station } & X, in feet & Y, in feet & $\begin{array}{c}\text { Change in gravity } \\
(\Delta \mathbf{G}) \text {, in milliGals }\end{array}$ \\
\hline DOR68 & 2349993 & 252683 & -1.15597741 \\
DOR72 & 2360208 & 260599 & 14.37016973 \\
HW4 & 2365143 & 278797 & -18.94592112 \\
J214 & 2353067 & 234136 & -63.33610535 \\
J217 & 2357232 & 269271 & -62.25244069 \\
J4 & 2354046 & 291915 & -76.5308078 \\
JOSRIDGE & 2352775 & 238369 & -48.81070645 \\
RE1 & 2351206 & 260808 & -11.25415119 \\
RE10 & 2354612 & 255180 & -18.10587899 \\
RE11 & 2353107 & 253605 & 3.4095101 \\
RE12 & 2352213 & 247985 & 2.27585865 \\
RE13 & 2352816 & 251691 & 0.89769682 \\
RE14 & 2353008 & 249717 & 0.02572826 \\
RE15 & 2352711 & 245901 & 1.9321282 \\
RE16 & 2351984 & 242689 & -15.95001837 \\
RE2 & 2353497 & 261928 & -16.48870649 \\
RE20 & 2358654 & 245236 & 7.86168871 \\
RE21 & 2360846 & 245403 & 19.03953311 \\
RE25 & 2362034 & 250737 & 24.5587134 \\
RE27A & 2363669 & 254916 & 24.1071194 \\
RE30 & 2360442 & 253617 & 12.09658343 \\
RE31 & 2357390 & 253980 & 7.55158502 \\
RE32 & 2356301 & 253157 & 0.66520072 \\
RE33 & 2367252 & 245057 & 52.42987406 \\
RE34 & 2354534 & 251370 & -3.26397509 \\
RE35 & 2353631 & 260441 & -8.61514844 \\
RE36 & 2361814 & 261093 & 18.73139952 \\
RE37 & 2358274 & 257224 & -10.31232279 \\
RE39 & 2350722 & 264326 & -14.89091714 \\
RE4 & 2357683 & 259802 & 6.42613506 \\
RE40 & 2350847 & 266261 & -24.21614755 \\
RE5 & 2353796 & 259481 & -3.34672394 \\
RE7 & 2352962 & 257949 & -5.93148376 \\
RE8 & 2354116 & 256866 & -16.16445758 \\
RE9 & 2357181 & 255983 & -14.81229518 \\
SLME & 2352014 & 256800 & -10.00196262 \\
VOLPK & 2349859 & 229185 & -35.26467283 \\
ZAP15 & 260808 & 2351206 & -22.35539539 \\
ZAP2 & 2348626 & 256194 & -73.86666211 \\
ZAP28 & 2354310 & 244906 & -31.58289749 \\
ZAP29 & 2348422 & 245551 & -15.6998672 \\
\hline & & & \\
\hline
\end{tabular}




\section{References Cited}

Ali, S.T., Akerley, J., Baluyut, E.C., Davatzes, N.C., Lopeman, J., Moore, J., Plummer, M., Spielman, P., Warren, I., and Feigl, K.L., 2016, Geodetic measurements and numerical models of deformationExamples from geothermal fields in the Western United States: Workshop on Geothermal Reservoir Engineering, 41st, Stanford, Calif., 2016, Proceedings, 7 p.

Bacon, C.R., and Duffield, W.A., 1980, Distribution of quaternary rhyolite domes of the Coso Range, California-Implications for extent of the geothermal anomaly: Journal of Geophysical Research, $v$. 85, no. B5, p. 2425-2433.

Blakely, R.J., 1995, Potential theory in gravity and magnetic applications: New York, Cambridge University Press, $441 \mathrm{p}$.

Bott, M.H.P., 1960, The use of rapid digital computing methods for direct gravity interpretation of sedimentary basins: Geophysical Journal of the Royal Astronomical Society, v. 3, p. 63-67.

Cleveland, W.S., 1993: Visualizing data: Summit, N.J., Hobart Press, 360 p.

Dobrin, M.B., and Savit, C.H., 1988, Introduction to geophysical prospecting: New York, McGraw Hill, $867 \mathrm{p}$.

Duffield, W.A., Bacon, C.R., and Dalrymple, G.B., 1980, Late Cenozoic volcanism, geochronology, and structure of the Coso Range, Inyo County, California: Journal of Geophysical Research, v. 85, no. B5, p. 2381-2404.

Fialko, Y., and Simons, M., 2000, Deformation and seismicity in the Coso geothermal area, Inyo County, California-Observations and modeling using satellite radar interferometry: Journal of Geophysical Research, v. 105, p. 21,781-21,793.

Jachens, R.C., and Moring, B.C., 1990, Maps of the thickness of Cenozoic deposits and the isostatic residual gravity over basement for Nevada: U.S. Geological Survey Open-File Report 90-404, 15 p., 2 plates, scale 1:1,000,000.

Longman, I.M., 1959, Formulas for computing the tidal accelerations due to the Moon and Sun: Journal of Geophysical Research, v. 64, no. 12, p. 2351-2355.

Lowrie, W., 1993, Fundamentals of geophysics: Cambridge University Press, 354 p.

Morelli, C., ed., 1974, The International Gravity Standardization Net, 1971: International Association of Geodesy Special Publication 4, 194 p.

Reudlink, R., Klees, R., Francis, O., Kusche, J., Schlesinger, R., Shabanloui, A., Sneeuw, N., and Timmen, L., 2014, High tilt susceptibility of the Scintrex CG-5 relative gravimeters: Journal of Geodesy, v. 88, p. 617-622, https://doi.org/10.1007/s00190-014-0705-0.

Sabin, A., Blake, K., Lazaro, M., Meade, D., Blankenship, D., Kennedy, M., McCulloch, J., DeOreo, S., Hickman, S., Glen, J., Kaven, O., Schoenball, M., Williams, C., Phelps, G., Faulds, J.E., Hinz, N., Calvin, W., Siler, D., and Robertson-Tait, A., 2016, Geologic setting of the West Flank, a FORGE site adjacent to the Coso geothermal field: Workshop on Geothermal Reservoir Engineering, 41st, Stanford, Calif., 2016, Proceedings, 11 p.

Scintrex Limited, 2006, CG-5 Scintrex Autograv system operation manual: Concord, Ontario, Scintrex Limited, 304 p.

Sen, P.K., 1968, Estimates of the regression coefficient based on Kendall's tau: Journal of the American Statistical Association, v. 63, p. 1379-1389, https://doi.org/10.2307/2285891.

Simon, J.I., Vazquez, J.A., Renne, P.R., Schmitt, A.K., Bacon, C.R. and Reid, M.R., 2009, Accessory mineral $\mathrm{U}-\mathrm{Th}-\mathrm{Pb}$ ages and ${ }^{40} \mathrm{Ar} /{ }^{39} \mathrm{Ar}$ eruption chronology, and their bearing on rhyolitic magma evolution in the Pleistocene Coso volcanic field, California: Contributions to Mineralogy and Petrology, v. 158, p. 421-446, https://doi.org/10.1007/s00410-009-0390-9. 
Telford, W.M., Geldart, L.P., and Sheriff, R.E., 1990, Applied geophysics (2d ed.): Cambridge University Press, $770 \mathrm{p}$.

Woolf, R., 2013, Time lapse gravity monitoring at Coso geothermal field: Golden, Colorado School of Mines, M.S. thesis, $66 \mathrm{p}$. 
ISSN 2331-1258 (online)

https://doi.org/10.3133/ofr20181053 